\title{
Oxidation State of Fe and Ti Ions Implanted in Yttria-Stabilized Zirconia Studied by XPS
}

\author{
B. A. van Hassel and A. J. Burggraaf \\ Laboratory for Inorganic Chemistry, Materials Science and Catalysis, Department of Chemical Technology, \\ University of Twente, P.O. Box 217, NL-7500 AE Enschede, The Netherlands
}

Received 18 December 1990/Accepted 21 March 1991

\begin{abstract}
The oxidation state of Fe and Ti ions implanted in yttria stabilized zirconia (YSZ) was studied by XPS (X-ray photoelectron spectroscopy) in combination with depth profiling using $\mathrm{Ar}^{+}$sputtering. In the "as-implanted" state of the sample $\mathrm{Fe}$ was found to be present as $\mathrm{Fe}^{3+}$, $\mathrm{Fe}^{2+}$ and as metallic $\mathrm{Fe}^{0}$. This is in agreement with earlier conversion electron Mössbauer Spectroscopy measurements. For Ti-implanted YSZ in the "as-implanted" state the majority of the $\mathrm{Ti}$ is present as $\mathrm{Ti}^{4+}, \mathrm{Ti}^{3+}$, and $\mathrm{Ti}^{2+}$ ions, while a part of the $\mathrm{Zr}$ cations is present in the divalent oxidation state $\left(\mathrm{Zr}^{2+}\right)$. After oxidation in air, the $\mathrm{Fe}$ and $\mathrm{Ti}$ ions are present only in the valence three and four oxidation states, respectively.
\end{abstract}

PACS: $79.60 . \mathrm{Eq}, 61.70 . \mathrm{Tm}$

X-ray photoelectron spectroscopy (XPS) is frequently used to study the chemical nature of surfaces [1]. It gives information on the chemical composition as well as the oxidation state of the elements present in the surface. Ion beams can be used for surface cleaning or depth profiling. Hence in principle it is possible to study the oxidation state of elements in thin films as a function of the depth.

During sputtering preferential removal of elements may occur. These effects originate from differences in the surface binding energies and from mass differences [2]. In oxides the lattice oxygen generally is sputtered preferentially with respect to the metal ions $[2,3]$. The remaining electrons of oxygen cause reduction of cations present in a thin surface layer, with a thickness comparable to the penetration depth of the bombarding ions [4]. It seems, however, not yet to be possible to correct sputtering depth profiles for these preferential sputtering effects.

This study, which is part of a larger research effort [5], is intended to give information on the oxidation state of $\mathrm{Fe}$ and Ti ions in the "as-implanted" state of YSZ. These results are of importance for the study of the structure [6] and electrochemical properties [7] of these implanted layers. Most information available on the charge state has been obtained with conversion electron Mössbauer spectroscopy (CEMS) [8-11]. With CEMS the oxidation state of the implanted ions, in a shallow surface layer of about $100 \mathrm{~nm}$ thickness, is analyzed in a non-destructive way. Few elements, however, have suitable isotopes for this technique. The charge state of ${ }^{57} \mathrm{Fe}$ ions [11-18] can be studied very well, but the charge state of Ti cannot.

In order to obtain results without any detailed description of the sputtering process at hand, a careful analysis of the evolution of the oxidation states of the cations as a function of the sputtering time is carried out with XPS. The data obtained from the samples in the "as-implanted" state are compared with the data, obtained under similar conditions, from samples with all cations in the highest oxidation state ("oxidized state"). From this analysis conclusions are drawn on the oxidation state of $\mathrm{Fe}$ and $\mathrm{Ti}$ ions in the "as-implanted" state of the YSZ sample.

A disadvantage of this method is the destructive nature of the depth profiling technique and the inability to correct for changes in the oxidation state of the cations during ion bombardment, making it still impossible to quantify the results. An advantage of the method is that the oxidation state of implanted ions can be studied for elements which lack suitable isotopes for Mössbauer spectroscopy.

\section{Experimental}

Yttria stabilized zirconia powder [Zircar, type: ZYP $\left.\left(\mathrm{ZrO}_{2}\right)_{0.87}\left(\mathrm{YO}_{1.5}\right)_{0.13}\right]$ was isostatically pressed $(400 \mathrm{MPa})$ and subsequently heated first for three hours at $1300^{\circ} \mathrm{C}$ and finally for three hours at $1400^{\circ} \mathrm{C}$. Rods were 
obtained with a density of $5.89 \mathrm{~g} \mathrm{~cm}^{-3}(=99 \%$ of theoretical density). From these YSZ rods discs were cut (diameter: $10 \mathrm{~mm}$, thickness: $1 \mathrm{~mm}$ ). The discs were mechanically polished, first with $\operatorname{SiC}(29,9,7$, and $5 \mu \mathrm{m})$ and finally with diamond paste ( 7 and $3 \mu \mathrm{m})$.

The ion implantations were performed at room temperature in a vacuum of $5 \times 10^{-5} \mathrm{~Pa}$. The YSZ discs were implanted with $15 \mathrm{keV} \mathrm{Fe}$ or $\mathrm{Ti}$, up to a dose of $8 \times 10^{16} \mathrm{at} \mathrm{cm}^{-2}$, using the isotope separator of the Laboratory for General Physics (LAN) of the State University of Groningen. The beam was perpendicular to the sample surface, with a current density of $2 \mu \mathrm{A} \mathrm{cm}^{-2}$. Further details concerning the ion implantation process can be found in $[5,6]$.

Due to the $\mathrm{Fe}$ or $\mathrm{Ti}$ implantation, the YSZ discs showed a brown metallic or silver colour, respectively. The chemical state of the sample after the ion implantation process and before any annealing treatment is given will be called, the "as-implanted" state of the sample. After oxidation of these discs in air at $400^{\circ} \mathrm{C}$ the Fe-implanted sample obtained an orange colour and the Ti-implanted sample regained its original white colour. This chemical state of the sample will be called the "oxidized state".

Rutherford backscattering (RBS) experiments have been performed with the $5 \mathrm{MeV}$ Van der Graaff accelerator of the LAN of the State university of Groningen. A more detailed description of the RBS analysis can be found in $[5,6]$.

$\mathrm{X}$-ray photoelectron spectroscopy (XPS) measurements were performed with the Kratos XSAM- 800 apparatus of the Centre for Materials Science (CMO) of Twente University. The spectra have been recorded with $\mathrm{Mg}-K_{\alpha 1,2}(1253.6 \mathrm{eV})$ radiation. The photoelectrons were analyzed in a concentric hemisphere analyzer (CHA) which was located perpendicular to the sample surface. The energy resolution of the CHA was $0.99 \mathrm{eV}$ (FWHM) at the pass energy of $20 \mathrm{eV}$. Background corrections were applied following the method developed by Shirley [19].

Corrections for surface charging (2-5 V) were applied using the $\mathrm{C} 1 \mathrm{~s}$ signal $(285.1 \mathrm{eV})$, of surface impurities, as a reference. This resulted in a binding energy of $530.2 \mathrm{eV}$ for the $\mathrm{O} 1 \mathrm{~s}$ electron. When the $\mathrm{C} 1 \mathrm{~s}$ signal disappeared due to sputtering than the $\mathrm{O} 1 \mathrm{~s}$ signal was taken as a reference. The deconvolution of the spectra was performed with a computer program also provided by Kratos. This program allows a maximum of 8 peaks to be fitted to the experimental data. Peak widths were not allowed to be larger than $3.5 \mathrm{eV}$.

In order to obtain a sputtering depth profile and to study the evolution of the oxidation state of the previous implanted $\mathrm{Fe}$ or Ti ions in time, a $3 \mathrm{keV} \mathrm{Ar}^{+}$ion beam was used with a sputter rate of $0.6 \mathrm{~nm} \mathrm{~min}{ }^{-1}$ for $\mathrm{Ta}_{2} \mathrm{O}_{5}$. The corresponding sputter rate for YSZ was calculated by adjusting the value of the sputter rate until a best agreement was obtained between the RBS and XPS depth profile. This resulted in a sputter rate of $0.6 \mathrm{~nm} \mathrm{~min}^{-1}$ and $0.43 \mathrm{~nm} \mathrm{~min}{ }^{-1}$ for respectively the Fe- or Ti-implanted layer in the "oxidized state". This difference in sputter rate may be due to an experimental problem in positioning the sample reproducibly in the $\mathrm{Ar}^{+}$ion beam.
For the quantitative analysis of the XPS data accurate atomic sensitivity factors had to be obtained [1]. Those values were obtained by comparing the RBS with the XPS depth profile. This method has been described previously $[5,6]$.

\section{Results and Discussion}

\subsection{Surface Modification}

Implantation depth profiles for the oxidized samples as determined by RBS are shown in Fig. 1 together with XPS results. The shape of the depth profiles differ from the Gaussian like peak shape expected for low dose ion implantation, due to the simultaneous occurrence of sputtering during high dose ion implantation. This results in a diffusion like dopant profile with a maximum concentration which is inversely proportional to its sputter yield in the compound target [20]. A more detailed study with ion scattering spectroscopy (ISS) showed that the outermost surface layer with an estimated thickness of less than $2 \mathrm{~nm}$ consisted mainly of $\mathrm{Fe}_{2} \mathrm{O}_{3}$ or $\mathrm{TiO}_{2}$. A more detailed discussion of the thermal stability and microstructure of the implanted layer can be found in $[5,6]$.

\subsection{XPS Results of Fe-Implanted YSZ}

Figure 2a. shows the photoelectron spectra for $\mathrm{Fe}\left(2 p_{3 / 2,1 / 2}\right)$ obtained after different times of $\mathrm{Ar}^{+}$sputtering in the case of the Fe-implanted YSZ sample in the "oxidized" state. The spectrum of $\mathrm{Fe}\left(2 p_{3 / 2}\right)$ for a nonsputtered sample shows a peak at $711.2 \mathrm{eV}$ binding energy and $2.5 \mathrm{eV}$ FWHM, after background subtraction. As shown in Table 1, this peak position corresponds to $\mathrm{Fe}^{3+}$ [21-23]. According to previously published CEMS measurements [11] all the Fe cations in the Fe depth profile of the oxidized sample are initially present in the trivalent state.

After $5 \mathrm{~min}$ of ion bombardment the peaks shift towards lower binding energies and a narrow peak appears at a binding energy of $706.7 \mathrm{eV}$ and $2 \mathrm{eV} \mathrm{FWHM}$. A deconvolution of the $2 p_{3 / 2}$ peaks was made using the parameters of Table 1 . The new lines were ascribed to suboxides according to literature data [21-22]. A deconvolution of the spectrum with respect to the original components is shown in Fig. 3a.

The stepwise reduction of the $\mathrm{Fe}$ cations in the $\mathrm{Fe}$ implanted YSZ sample as a function of the sputtering time is clearly shown in Fig. 4a. The apparent existence of $\mathrm{Fe}$ species in the reduced state in deeper layers of this oxidized sample is due to the preferential sputtering of oxygen and a corresponding change in oxidation state of the $\mathrm{Fe}$ cations during ion bombardment. These measurements performed on the oxidized sample indicate how severely the oxidation state of the Fe cations is affected by ion bombardment.

The measurements discussed above have been repeated for the Fe-implanted sample in the "as-implanted" 

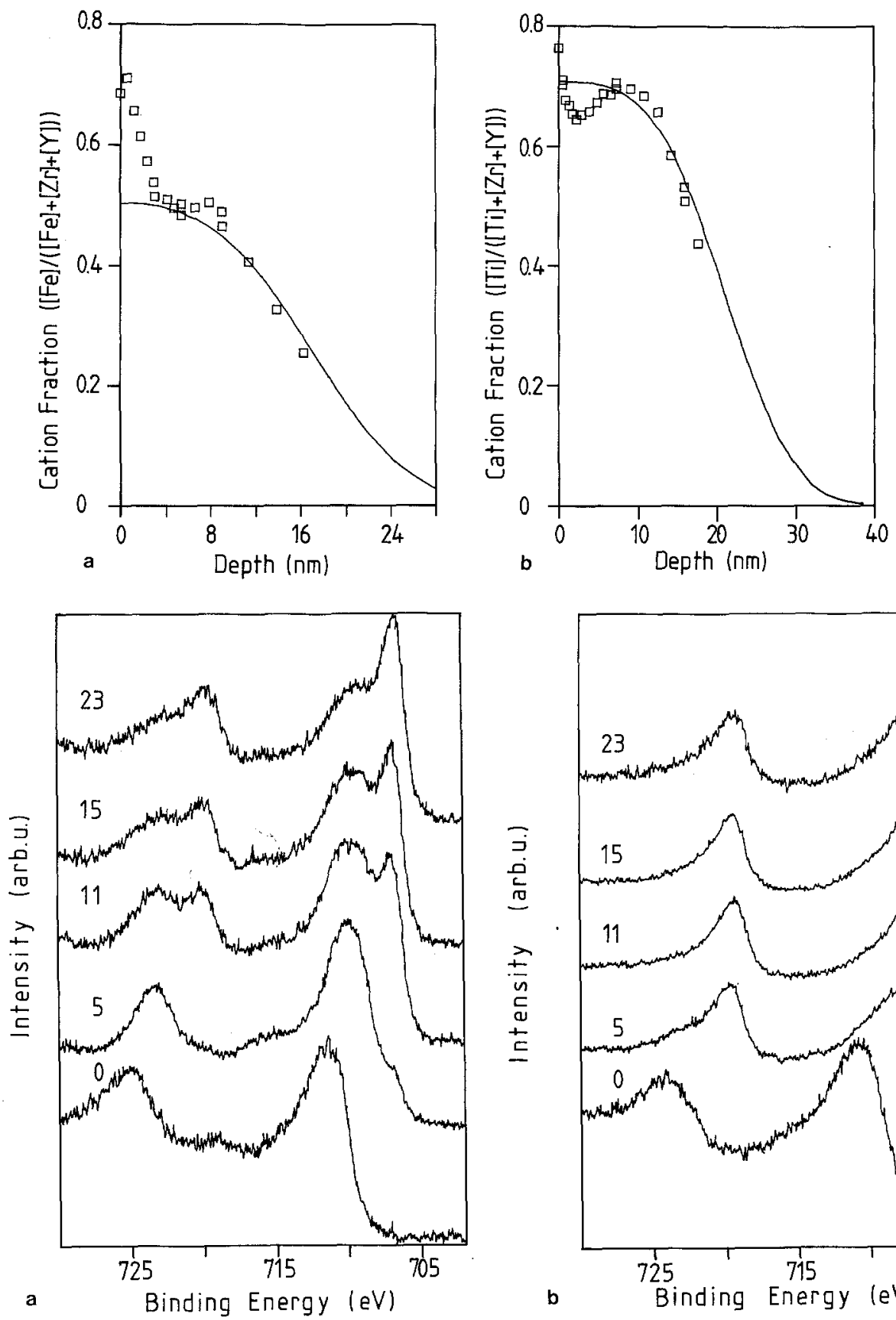

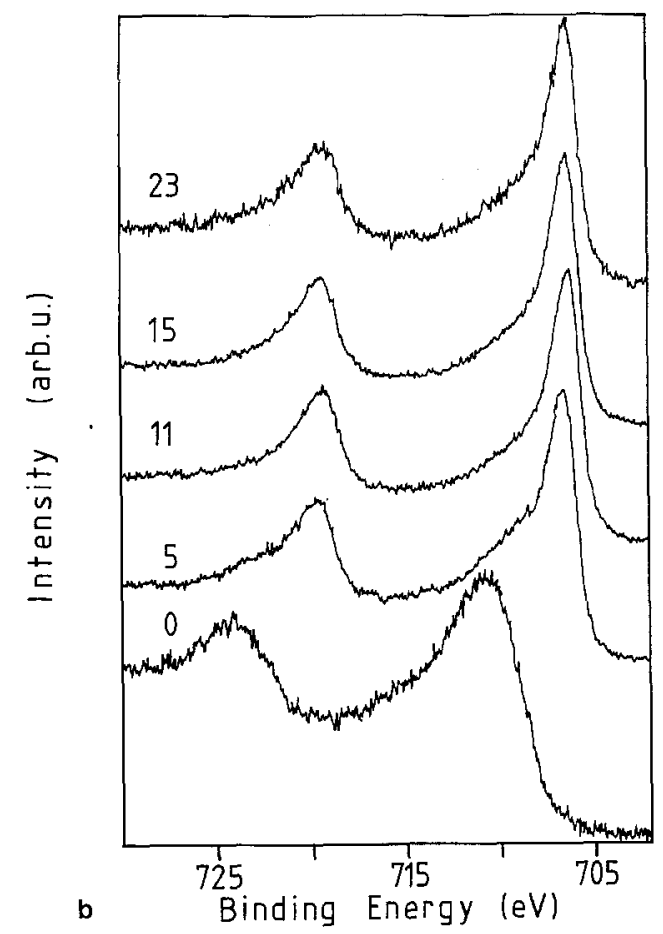

Fig. 1. Depth profile of the implanted ions in YSZ after oxidation, presented as cation fraction, as determined by XPS combined with sputtering (squares) and RBS (solid lines), (a) for $15 \mathrm{keV} \mathrm{Fe}$ and (b) for $15 \mathrm{keV} \mathrm{Ti}$, both at a dose of $8 \times 10^{16} \mathrm{at} \mathrm{cm}^{-2}$

Table 1. Binding energies of $\mathrm{Fe}$ in $\mathrm{YSZ}$

\begin{tabular}{lllllll}
\hline $\begin{array}{l}\text { Oxida- } \\
\text { tion } \\
\text { state }\end{array}$ & Line & $\begin{array}{l}E_{\mathrm{b}} \\
{[\mathrm{eV}]}\end{array}$ & $\begin{array}{l}\text { FWHM } \\
{[\mathrm{eV}]}\end{array}$ & $\begin{array}{l}E_{\mathrm{b}} \\
{[\mathrm{eV}]}\end{array}$ & $\begin{array}{l}\text { FWHM } \\
{[\mathrm{eV}]}\end{array}$ & $\begin{array}{l}E_{\mathrm{b}} \\
{[\mathrm{eV}]} \\
\text { after [22] }\end{array}$ \\
\hline $\mathrm{Fe}^{3+}$ & $2 p_{3 / 2}$ & $710.7 \pm 0.2$ & $3.4 \pm 0.2$ & 710.8 & 3.3 & 711.0 \\
$\mathrm{Fe}^{2+}$ & $2 p_{3 / 2}$ & $709.2 \pm 0.2$ & $3.0 \pm 0.6$ & 709.4 & 3.3 & 709.5 \\
$\mathrm{Fe}^{0}$ & $2 p_{3 / 2}$ & $706.7 \pm 0.2$ & $1.7 \pm 0.2$ & 707.2 & 2.0 & 706.9 \\
\hline
\end{tabular}

state. The corresponding spectra are shown in Fig. $2 \mathrm{~b}$ and the results of the deconvoltuion are shown in Figs. $3 \mathrm{~b}$ and $4 \mathrm{~b}$. The outermost surface layer was oxidized due to the transfer from the "end station" of the ion implanter to the XPS apparatus in air. But judging from the peak width, the sample transfer did not result in a complete oxidation to $\mathrm{Fe}^{3+}$, since an appreciable amount of $\mathrm{Fe}^{2+}$ is still present in the spectrum of the non-sputtered sample.

Comparing the XPS spectra in Fig. 2 taken after identical sputtering times (e.g., $11 \mathrm{~min}$ ) convincingly 

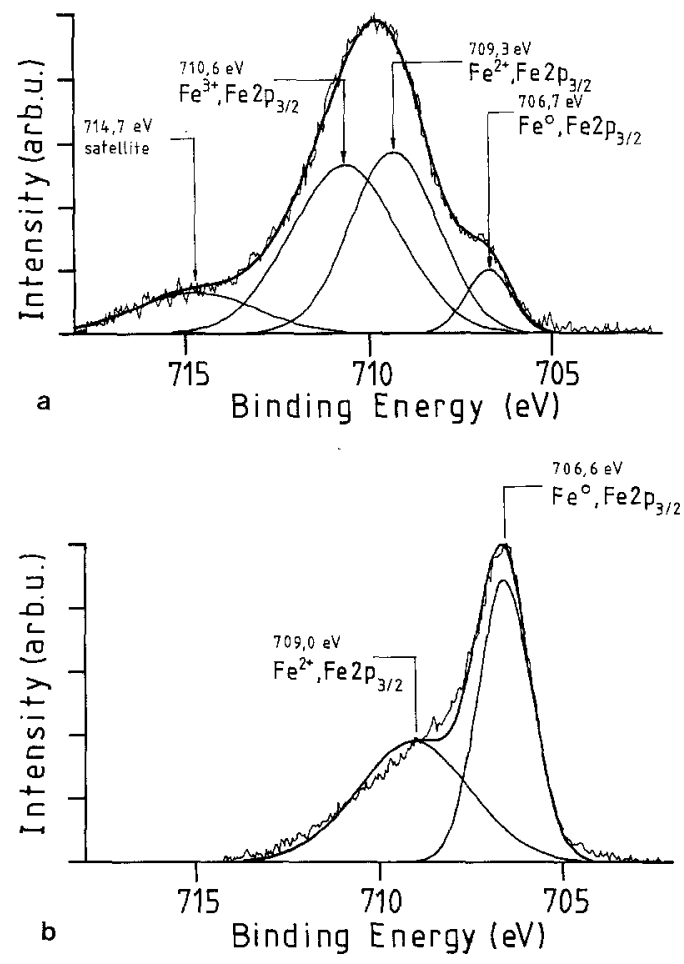

Fig. 3. Deconvolution of the Fe $2 p_{3 / 2}$ peak, recorded after 5 min of sputtering, (a) for the oxidized sample and (b) for the "as-implanted" sample
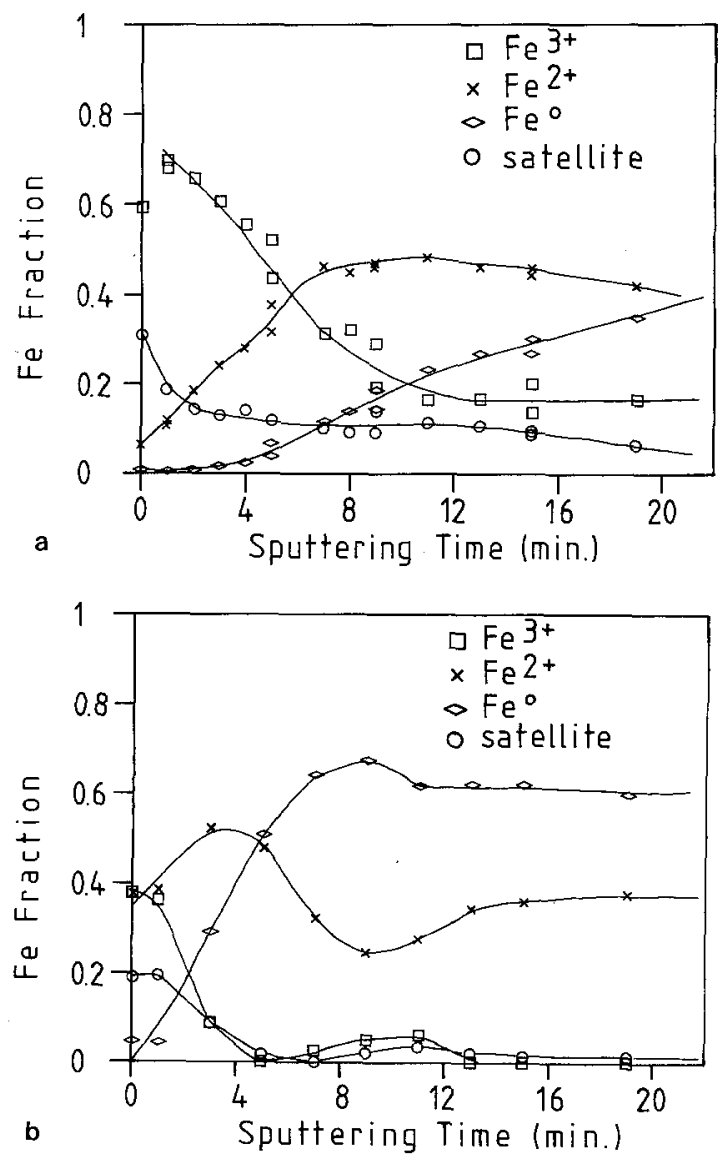

Fig. 4. Fractions of the different oxidation state of $\mathrm{Fe}$ as function of sputtering time, (a) for the oxidized sample and (b) for the "asimplanted" sample
Table 2. The oxidation state of implanted ${ }^{57} \mathrm{Fe}$ ions in YSZ obtained by CEMS [11], as the fraction of the total number of Fe atoms in the implanted layer

\begin{tabular}{llllll}
\hline $\begin{array}{l}\text { Energy } \\
{[\mathrm{keV}]}\end{array}$ & $\begin{array}{l}\text { Dose } \\
{\left[\mathrm{atcm} \mathrm{cm}^{-2}\right]}\end{array}$ & \multicolumn{2}{l}{ Oxidation state } & & \\
\cline { 3 - 6 } & & $\mathrm{Fe}^{0}$ & & $\mathrm{Fe}^{2+}$ & $\mathrm{Fe}^{3+}$ \\
\hline 15 & $8 \times 10^{16}$ & 0.27 & 0.14 & 0.25 & 0.34 \\
\hline
\end{tabular}

shows the presence of a larger amount of reduced $\mathrm{Fe}$ species $\left(\mathrm{Fe}^{2+}\right.$ and $\left.\mathrm{Fe}^{0}\right)$ in the "as-implanted" state than in the oxidized state of the Fe-implanted YSZ sample. Comparing the depth profiles of the various $\mathrm{Fe}$ species of Fig. 4 also leads to the same conclusion. In the "asimplanted" state, a steep increase in the metallic $\mathrm{Fe}^{0}$ fraction is observed, whereas in the "oxidized" state only a very gradual increase takes place as a function of sputtering depth. These results suggest $\mathrm{Fe}^{3+}$ to be mainly present in the outermost surface layer for the sample in the "asimplanted" state.

This confirms the results obtained by CEMS that $\mathrm{Fe}$ is present as $\mathrm{Fe}^{3+}, \mathrm{Fe}^{2+}$, and $\mathrm{Fe}^{0}$ in the "as-implanted" state of the sample [11]. The relative abundance of each $\mathrm{Fe}$ oxidation state, as obtained by CEMS, integrated over the first $100 \mathrm{~nm}$ of the Fe-implanted sample, is shown in Table 2.

\subsection{XPS Results of Ti Implanted YSZ}

Figure 5a shows the photoelectron spectra for $\operatorname{Ti}\left(2 p_{3 / 2,1 / 2}\right)$ obtained after different times of sputtering in the case of the Ti-implanted YSZ sample in the "oxidized" state. The spectrum of $\operatorname{Ti}\left(2 p_{3 / 2,1 / 2}\right)$ for a non-sputtered sample shows peaks at $458.5 \mathrm{eV}$ binding energy and $1.7 \mathrm{eV}$ FWHM (Ti2 $p_{3 / 2}$ ) and at $464.1 \mathrm{eV}$ binding energy and $2.5 \mathrm{eV}$ FWHM (Ti2 $\left.2 p_{1 / 2}\right)$. As shown in Table 3 , these peak positions correspond well to the literature data of $\mathrm{Ti}^{4+}[4,21]$.

After 5 min of ion bombardment the peaks broaden. A deconvolution of the peaks was made using the parameters of Table 3 . The new lines were ascribed to suboxides according to literature data $[4,21]$. A deconvolution of the spectrum with respect to the original components is shown in Fig. 6a. The deconvolution of the spectra was performed as described above. In order to obtain consistent results the distance between the $2 p_{3 / 2}$ and $2 p_{1 / 2}$ peak of each oxidation state was fixed, as was the intensity ratio. The peak width was not allowed larger than $2.5 \mathrm{eV}$. The stepwise reduction of the Ti cations in the Ti-implanted YSZ sample as a function of the sputtering time is clearly shown in Fig. 7a.

It is assumed for this oxidized sample that all the Ti cations in the Ti depth profile initially are present in the four valent oxidation state. The apparent existence of $\mathrm{Ti}$ species in the reduced state in deeper layers of this oxidized sample is due to the preferential sputtering of oxygen and a corresponding change in oxidation state of the Ti cations during ion bombardment. 

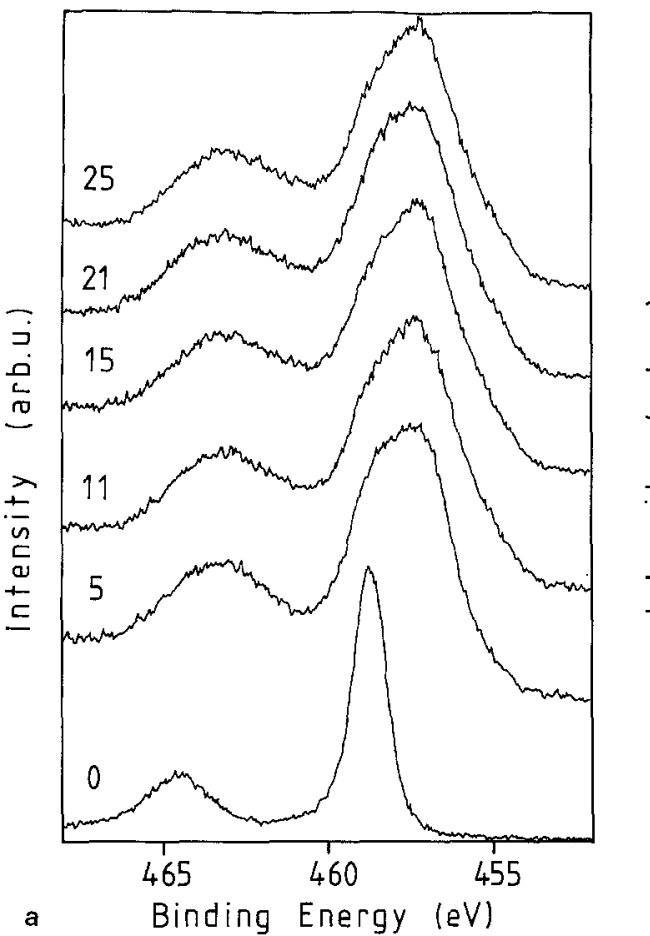

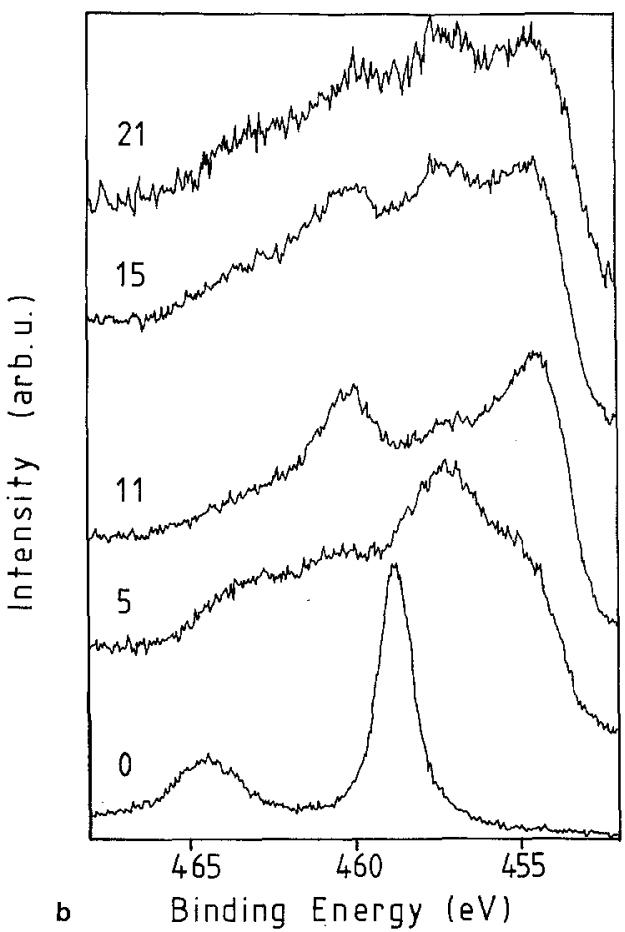

Fig. 5. Photoelectron spectra for $\operatorname{Ti}\left(2 p_{3 / 2,1 / 2}\right)$ recorded after different sputtering times, (a) for the oxidized sample, (b) for the "as-implanted" sample. Indicated sputtering times are in minutes
The measurements discussed above have been repeated for the Ti-implanted sample in the "as-implanted" state. The corresponding spectra are shown in Fig. $5 \mathrm{~b}$ and the results of the deconvolution are shown in Figs. $6 \mathrm{~b}$ and $7 \mathrm{~b}$. As in the case of the Fe-implanted sample, the outermost surface layer of this sample was also oxidized due to the sample transfer.

Comparing the XPS spectra in Fig. 5 after the same sputtering time convincingly shows the presence of a larger amount of reduced $\mathrm{Ti}$ species $\left(\mathrm{Ti}^{3+}\right.$ and $\left.\mathrm{Ti}^{2+}\right)$ in the "as-implanted" state than in the oxidized state of the Tiimplanted YSZ sample. This is shown more quantitatively in Fig. 7. In the "as-implanted" state, the $\mathrm{Ti}^{4+}$ fraction drops much faster as a function of the sputtering time and it ends at a lower level in comparison with the oxidized state. The $\mathrm{Ti}^{3+}$ fraction initially shows a much steeper rise as a function of time in the "as-implanted" state than in the "oxidized" state but finally decreases to a lower level. In the "oxidized" state, the $\mathrm{Ti}^{2+}$ fraction shows a slow increase with sputtering time and ends up at a level below both the $\mathrm{Ti}^{4+}$ and $\mathrm{Ti}^{3+}$ fraction, whereas in the "asimplanted" state the $\mathrm{Ti}^{2+}$ fraction increases much faster and ends at a level higher than both the $\mathrm{Ti}^{4+}$ and $\mathrm{Ti}^{3+}$ fraction. The $\mathrm{Ti}^{0}$ species are hardly present in the "oxidized" sample, but some increase in the $\mathrm{Ti}^{\circ}$ fraction can be observed for the "as-implanted" sample.

In our opinion, this leads to the conclusion that part of the reduced Ti species in the "as-implanted" state of the sample, should already have been present before the ion bombardment was started. Thus the Ti cations are present as $\mathrm{Ti}^{4+}, \mathrm{Ti}^{3+}, \mathrm{Ti}^{2+}$ in the "as-implanted" state of the sample. The amount of implanted ions present in a metallic state $\left(\mathrm{i} . e . \mathrm{Ti}^{\mathrm{O}}\right.$ ), if present, is far less than in the case of Fe-implanted YSZ in the "as-implanted" state.

A more quantitative conclusion on the relative abundances of the Fe or Ti species in different oxidation states as a function of the depth is not possible, because until now corrections of the sputtering depth profiles for the

Table 3. Binding energies of Ti in YSZ

\begin{tabular}{llllllll}
\hline $\begin{array}{l}\text { Oxida- } \\
\text { tion } \\
\text { state }\end{array}$ & Line & $\begin{array}{l}E_{\mathrm{b}} \\
{[\mathrm{eV}]}\end{array}$ & $\begin{array}{l}\text { FWHM } \\
{[\mathrm{eV}]}\end{array}$ & $\begin{array}{l}E_{\mathrm{b}} \\
{[\mathrm{eV}]}\end{array}$ & $\begin{array}{l}\text { FWHM } \\
{[\mathrm{eV}]}\end{array}$ & $\begin{array}{l}E_{\mathrm{b}} \\
{[\mathrm{eV}]}\end{array}$ & $\begin{array}{l}\text { FWHM } \\
{[\mathrm{eV}]}\end{array}$ \\
\hline $\mathrm{Ti}^{4+}$ & $2 p_{3 / 2}$ & $458.5 \pm 0.1$ & $1.7 \pm 0.2$ & 458.7 & 1.5 & 458.9 & 1.6 \\
& $2 p_{1 / 2}$ & $464.2 \pm 0.1$ & $2.5 \pm 0.1$ & 464.6 & 2.5 & 464.6 & 2.5 \\
$\mathrm{Ti}^{3+}$ & $2 p_{3 / 2}$ & $457.0 \pm 0.1$ & $2.5 \pm 0.1$ & 457.2 & 2.0 & 457.2 & 1.9 \\
& $2 p_{1 / 2}$ & $462.9 \pm 0.1$ & $2.5 \pm 0.2$ & 463.0 & 2.5 & 462.9 & 2.4 \\
$\mathrm{Ti}^{2+}$ & $2 p_{3 / 2}$ & $455.3 \pm 0.1$ & $1.9 \pm 0.1$ & 455.3 & 2.0 & 455.2 & 1.9 \\
& $2 p_{1 / 2}$ & $461.0 \pm 0.1$ & $2.7 \pm 0.1$ & 461.0 & 2.3 & 461.0 & 2.4 \\
$\mathrm{Ti}^{0}$ & $2 p_{3 / 2}$ & $453.2 \pm 0.2$ & $1.5 \pm 0.1$ & & & 453.6 & 1.6 \\
& $2 p_{1 / 2}$ & $459.6 \pm 0.2$ & $1.8 \pm 0.1$ & & & 460.0 & 2.0 \\
\hline
\end{tabular}



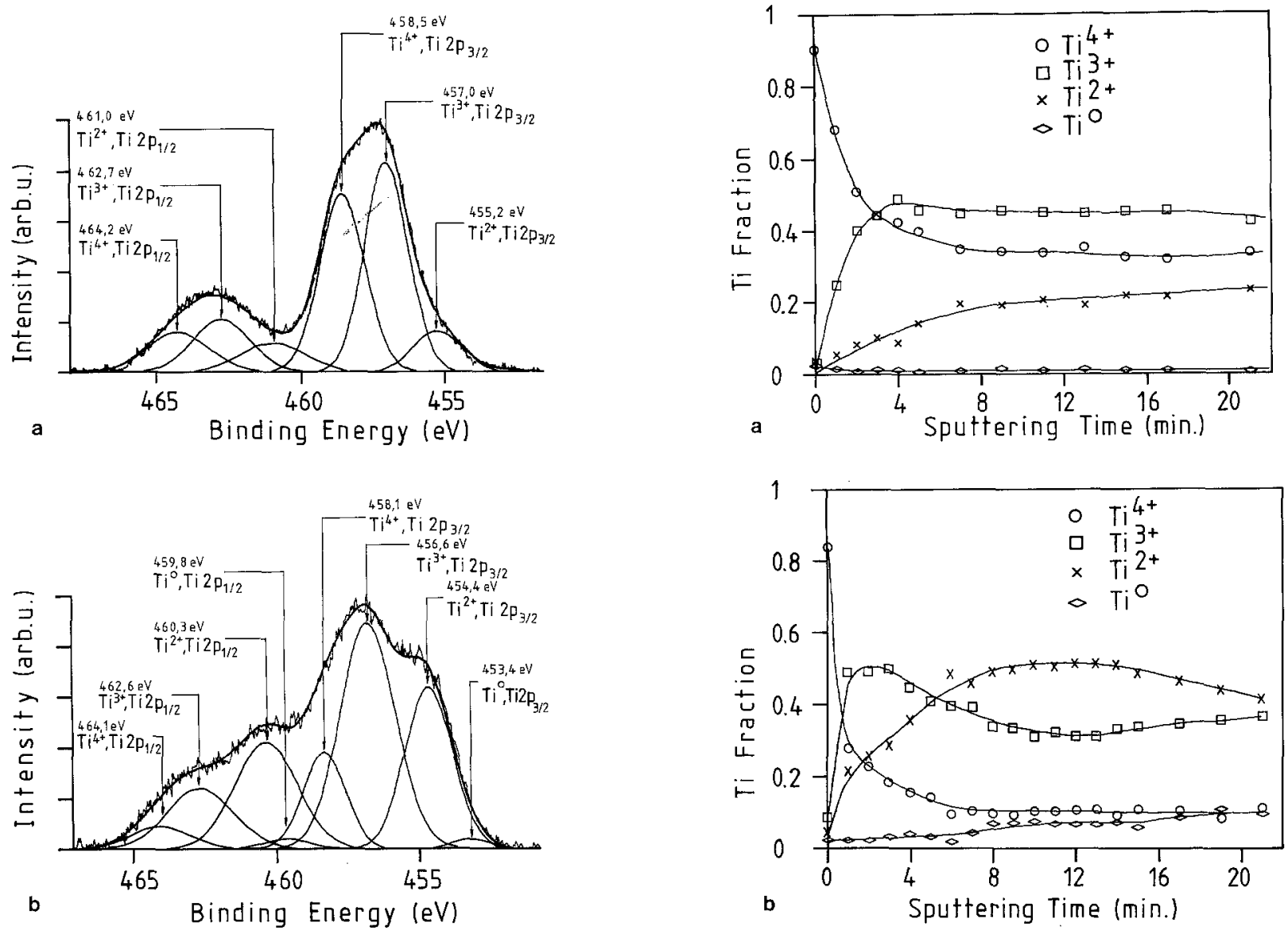

Fig. 6. Deconvolution of the Ti $2 p_{3 / 2}$ peak, recorded after $5 \mathrm{~min}$ of sputtering, (a) for the oxidized sample and (b) for the "as-implanted" sample

preferential sputtering of oxygen and the corresponding change in oxidation state of the cations present cannot be performed.

\subsection{Oxidation State of $\mathrm{Zr}$}

The implantation of Fe or Ti in yttria-stabilized zirconia affects the oxidation state of the $\mathrm{Zr}^{4+}$ cations. This is illustrated in Fig. 8 with photoelectron spectra for $\mathrm{Zr}$ $\left(3 d_{5 / 2,3 / 2}\right)$ in the case of Ti-implanted yttria stabilized zirconia. Both in the "oxidized" state as in the "asimplanted" state of the sample, the spectrum of $\operatorname{Zr}\left(3 d_{5 / 2,3 / 2}\right)$ for a non-sputtered sample shows peaks at $182.2 \mathrm{eV}$ binding energy and $1.4 \mathrm{eV} \mathrm{FWHM}\left(\mathrm{Zr} 3 d_{5 / 2}\right)$ and at $184.5 \mathrm{eV}$ binding energy and $1.4 \mathrm{eV} \mathrm{FWHM}\left(\mathrm{Zr} 3 d_{3 / 2}\right)$, as shown in Fig. 8a. According to literature (Table 4) those peaks correspond to $\mathrm{Zr}^{4+}$ [4].

In the "oxidized" state of the Ti implanted sample, $15 \mathrm{~min}$ of $\mathrm{Ar}^{+}$sputtering results in a broadening of the $\mathrm{Zr}^{4+}$ peaks from $1.4 \mathrm{eV}$ (FWHM) to $1.8 \mathrm{eV}$ (FWHM), but no significant amount of $\mathrm{Zr}$ in a lower oxidation state is found (Fig. 8b). Hence $\mathrm{Ar}^{+}$sputtering does not result in the reduction of the $\mathrm{Zr}^{4+}$ cations. In the "as-implanted" state of the sample, $15 \mathrm{~min}$ of $\mathrm{Ar}^{+}$sputtering resulted also in a peak broadening from $1.4 \mathrm{eV}$ FWHM to $2.0 \mathrm{eV}$

Fig. 7. Fractions of the different oxidation state of $\mathrm{Ti}$ as function of sputtering time, (a) for the oxidized sample and (b) for the "asimplanted" sample

FWHM, but two new peaks are clearly present at $181.0 \mathrm{eV}$ binding energy and $2.0 \mathrm{eV}$ FWHM and at $183.3 \mathrm{eV}$ binding energy and $2.0 \mathrm{eV}$ FWHM (Fig. 8c). Those new peaks can be ascribed to $\mathrm{Zr}^{2+}$, resulting from the ion implantation procedure.

\section{Conclusions}

The oxidation state of elements present in a thin surface layer can be qualitatively studied as a function of the depth by XPS in combination with sputtering. Full quantification of the results is not yet possible due to an incomplete understanding of the preferential effects during sputtering. The preferential sputtering of oxygen for instance seriously affects the oxidation state of the implanted transition metal cations whereas the oxidation state of $\mathrm{Zr}$ is not influenced.

From the XPS measurements in combination with sputtering it can be concluded that the implantation of $\mathrm{Fe}$ in YSZ results in a non-stoichiometric surface layer in which the $\mathrm{Fe}$ cations are present as metallic $\mathrm{Fe}^{0}$, and as $\mathrm{Fe}^{2+}$ and $\mathrm{Fe}^{3+}$ ions. This was concluded previously from CEMS measurements. The implantation of Ti results also in a non-stoichiometric surface layer, in which the $\mathrm{Ti}$ cations are present as $\mathrm{Ti}^{4+}, \mathrm{Ti}^{3+}$, and $\mathrm{Ti}^{2+}$ ions. The 

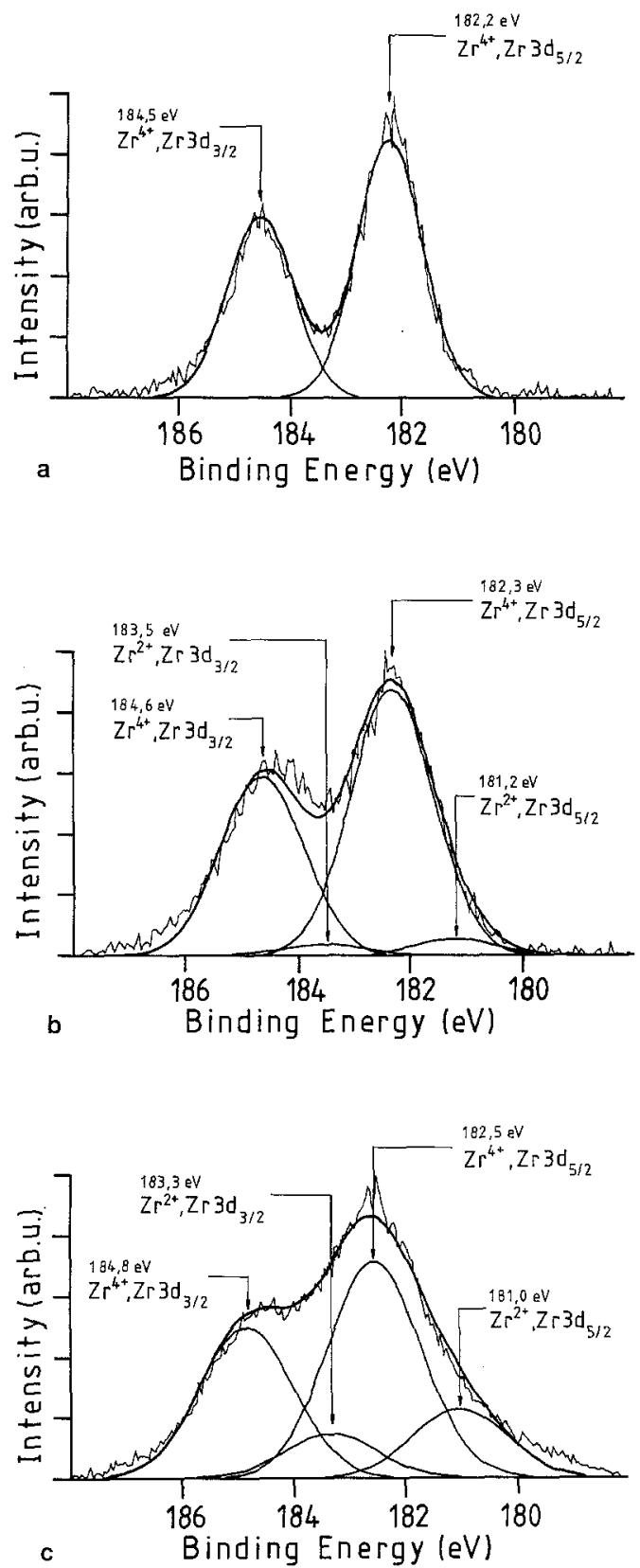

Fig. 8. Photoelectron spectra for $\operatorname{Zr}\left(3 p_{5 / 2,3 / 2}\right)$ in Ti-implanted YSZ recorded for the oxidized sample: (a) before sputtering and (b) after 15 min sputtering, and for the "as-implanted" sample: (c) after 15 min sputtering fraction of the Ti cations present in a metallic state was found to be not significant. It can also be concluded that in the "as-implanted" state of the Ti-implanted yttriastabilized zirconia sample, the $\mathrm{Zr}$ cations are mainly present in the valence four oxidation state $\left(\mathrm{Zr}^{4+}\right)$, but some are present in the divalent oxidation state $\left(\mathrm{Zr}^{2+}\right)$.

After oxidation in air at $400^{\circ} \mathrm{C}$, the stoichiometry of the samples is restored and all cations are present in their highest oxidation state $\left(\mathrm{Zr}^{4+}, \mathrm{Y}^{3+}, \mathrm{Fe}^{3+}\right.$, and $\left.\mathrm{Ti}^{4+}\right)$.

Acknowledgement. The authors appreciate the cooperation with the Laboratorium voor Algemene Natuurkunde (LAN) of the State university of Groningen. They are grateful to J. J. Smit for the ion implanter facilities. They thank Dr. D. O. Boerma of the state university of Groningen for his supervision during the RBS measurements. They are indebted to Ing. A. H. J. van den Berg of the Centre for Materials Science of Twente University for measuring the XPS depth profiles. The investigations were supported by the Netherlands Foundation for Chemical Research (SON) with financial aid from the Netherlands Organisation for Scientific Research (NWO).

\section{References}

1. M. Grasserbauer, H.J. Dudek, M.F. Ebel (eds.): Angewandte Oberflächen Analyse mit SIMS, AES, XPS (Springer, Berlin, Heidelberg 1985)

2. J.B. Malherbe, S. Hofmann, J.M. Sanz: Appl. Surf. Sci. 27, 355 (1986)

3. R. Kelly: In Ion Beam Modification of Insulators, Beam Modification of Materials 2, ed. by P. Mazzoldi, G.W. Arnold (Elsevier, Amsterdam 1987) pp. 57-113

4. S. Hofmann, J.M. Sanz: J. Trace Microprobe Techniques, 1, 213 $(1982 / 3)$

5. B.A. van Hassel: Transport and oxygen transfer properties of ion implanted yttria stabilized zirconia, $\mathrm{PhD}$ Thesis, University of Twente, Enschede, The Netherlands (1990)

6. B.A. van Hassel, A.J. Burggraaf: Submitted for publication in Appl. Phys. A

7. B.A. van Hassel, B.A. Boukamp, A.J. Burggraaf: To be published

8. B.D. Sawicka, J.A. Sawicki: In Mössbauer Spectroscopy II, ed. by U. Gonser. Topics Curr. Phys. 25 (Springer, Berlin, Heidelberg 1981) pp. $139-166$

9. J.A. Sawicki, G. Abouchacra, J. Serughetti, A. Perez: Nucl. Instrum. Meth. B 16, 355 (1986)

10. J. Li, Bai-Xin, Liu, Heng-De Li, W. Wang, N.F. Gao: Nucl. Instrum. Meth. B 18, 251 (1987)

11. A.J. Burggraaf, D. Scholten, B.A. van Hassel: Nucl. Instrum. Meth. B 32, 32 (1988)

12. C.J. McHargue, G.C. Farlow, P.S. Sklad, C.W. White, A. Perez, N. Kornilios, G. Marest: Nucl. Instrum. Meth. B 19/20, 813 (1987)

Table 4. Binding energies of $\mathrm{Zr}$ in YSZ

\begin{tabular}{llllll}
\hline $\begin{array}{l}\text { Oxidation } \\
\text { state }\end{array}$ & Line & $\begin{array}{l}E_{\mathrm{b}} \\
{[\mathrm{eV}]}\end{array}$ & $\begin{array}{l}\text { FWHM } \\
{[\mathrm{eV}]}\end{array}$ & $\begin{array}{l}E_{\mathrm{b}} \\
{[\mathrm{eV}]}\end{array}$ & $\begin{array}{l}\text { FWHM } \\
{[\mathrm{eV}]}\end{array}$ \\
\hline $\mathrm{Zr}^{4+}$ & $3 d_{5 / 2}$ & $182.2 \pm 0.1$ & $1.8 \pm 0.2$ & 182.3 & 1.8 \\
& $3 d_{3 / 2}$ & $184.5 \pm 0.1$ & $1.8 \pm 0.2$ & 184.7 & 1.8 \\
$\mathrm{Zr}^{2+}$ & $3 d_{5 / 2}$ & $181.0 \pm 0.1$ & $1.8 \pm 0.2$ & 180.7 & 1.8 \\
& $3 d_{3 / 2}$ & $183.3 \pm 0.1$ & $1.8 \pm 0.2$ & 183.1 & 1.8 \\
$\mathrm{Zr}^{0}$ & $3 d_{5 / 2}$ & & & 178.5 & 1.8 \\
& $3 d_{3 / 2}$ & & & 180.9 & 1.8 \\
\hline
\end{tabular}


13. A. Perez, G. Marest, B.D. Sawicka, J.A. Sawicki, T. Tyliszczak: Phys. Rev. B 28, 1227 (1983)

14. J.A. Sawicki, G. Marest, B. Cox: In Structure-Property Relationships in Surface-Modified Ceramics, NATO ASI Series E: Applied Sciences-Vol. 170, ed. by C.J. McHargue, R. Kossowsky, W.O. Hofer (Kluwer, Dordrecht 1989) pp. 209-218

15. S. Massouh, A. Perez, J. Serughetti: Nucl. Instrum. Meth. B 32, $71(1988)$

16. N. Kornilios, G. Marest, A. Perez, M. Brunel, B. Gilles, P.H. Gerard, F. Ravel: Nucl. Instrum. Meth. B 19/20, 860 (1987)
17. A. Perez, M. Treilleux, T. Capra, D.L. Griscom: J. Mater. Res. 2 , $910(1987)$

18. C.J. McHargue: Int. Metals Rev. 31, 49 (1986)

19. D.A. Shirley: Phys. Rev. B 5, 4709 (1972)

20. H. Ryssel, I. Ruge: Ion Implantation (Wiley, Chichester 1986)

21. T. Choudhury, S.O. Saied, J.L. Sullivan, A.M. Abbot: J. Phys. D 22, 1185 (1989)

22. N.S. McIntyre, D.G. Zetaruk: Anal. Chem. 49, 1521 (1977)

23. A. Fujimori, M. Saeki, N. Kimizuka, M. Taniguchi, S. Suga: Phys. Rev. B 34, 7318 (1986) 